\title{
Alveolar soft part sarcoma metastatic to the breast: a case report
}

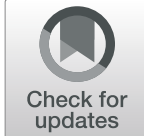

\author{
Yuka Asano', Shinichiro Kashiwagi ${ }^{1 *}$ (D, Koji Takada', Sadao Tokimasa², Tsutomu Takashima', Masahiko Ohsawa ${ }^{3}$, \\ Kosei Hirakawa ${ }^{1}$ and Masaichi Ohira ${ }^{1}$
}

\begin{abstract}
Background: Alveolar soft part sarcoma (ASPS) is an extremely rare neoplasm that tends to occur in the lower limbs of children and adolescents. Metastatic breast tumors constitute $0.5-2.0 \%$ of all malignant mammary neoplasms, and cases of ASPS with mammary metastases are very rare.

Case presentation: Three years ago, an 11-year-old girl presented to the hospital with pain in the right jaw after becoming aware of a mass in the right cheek. After detailed examination, the patient was diagnosed with ASPS with the primary tumor in the right cheek and multiple lung metastases, and chemotherapeutic treatment was initiated. One year later, accumulation of fluorodeoxyglucose (FDG) was observed in the right front of the skull (standardized uptake value (SUV)-max 2.8) and left breast (SUV-max 2.4) using FDG-positron emission tomography (PET) / computed tomography (CT). Ultrasonography revealed the mammary tumor as a hypoechoic, internally heterogeneous mass measuring $22.4 \times 16.2 \times 21.1 \mathrm{~mm}$ with a rich blood supply. Using pathological findings of core-needle biopsy, we diagnosed it as ASPS. Based on the above information, we made a diagnosis of ASPS with left mammary and cranial metastases. Due to chemoresistance, surgical excision was selected as the mode of treatment; resection of the metastatic cranial bone was performed first, and partial mastectomy of the left breast was performed in two stages. Postoperative conditions were good, and we are currently performing regular follow-ups (visual palpation every 3 months and semi-annual mammary gland ultrasonography).

Conclusions: We have reported an extremely rare case of ASPS with mammary metastasis with some reference-based discussion. In our case, disease control was obtained by a combination of drug therapy and surgical treatment.
\end{abstract}

Keywords: alveolar soft part sarcoma, mammary tumor, surgery, FDG-PET, metastatic breast tumor

\section{Background}

Alveolar soft part sarcoma (ASPS) is an extremely rare neoplasm that tends to occur in the lower limbs of children and adolescents and was first described by Christopherson et al. in 1952 [1, 2]. Metastatic breast tumors constitute $0.5-2.0 \%$ of all malignant mammary neoplasms [3, 4], and cases of ASPS with mammary metastases are very rare [5-7]. Here, we report a case of ASPS with mammary metastasis with some reference-based discussion.

\footnotetext{
*Correspondence: spqv9ke9@view.ocn.ne.jp

${ }^{1}$ Department of Breast and Endocrine Surgery, Osaka City University Graduate School of Medicine, 1-4-3 Asahi-machi, Abeno-ku, Osaka 545-8585, Japan

Full list of author information is available at the end of the article
}

\section{Case presentation}

Three years ago, an 11-year-old girl presented to the hospital with pain in the right jaw after becoming aware of a mass in her right cheek. After detailed examination, the patient was diagnosed with ASPS with primary tumor in the right cheek and multiple lung metastases, and chemotherapeutic treatment was initiated. After receiving 1 cycle of VAC therapy (vincristine [2 mg], actinomycin D [0.045 mg/kg], and cyclophosphamide $\left.\left[1.2 \mathrm{~g} / \mathrm{m}^{2}\right]\right)$, the patient developed grade 4 neutropenia. After this treatment, the patient received 1 cycle of the treatment regimen prescribed for rhabdomyosarcoma (vincristine [2 $\mathrm{mg}]$, pirarubicin $\left[60 \mathrm{mg} / \mathrm{m}^{2}\right]$, cyclophosphamide $\left[1.2 \mathrm{~g} / \mathrm{m}^{2}\right]$, cisplatin $\left.\left[20 \mathrm{mg} / \mathrm{m}^{2}\right]\right)$ and 1 cycle of ifosfamide $(1800 \mathrm{mg} /$ $\left.\mathrm{m}^{2}\right)$, etoposide $\left(100 \mathrm{mg} / \mathrm{m}^{2}\right)$, actinomycin $\mathrm{D}(0.045 \mathrm{mg} / \mathrm{kg})$,

(c) The Author(s). 2019 Open Access This article is distributed under the terms of the Creative Commons Attribution 4.0 International License (http://creativecommons.org/licenses/by/4.0/), which permits unrestricted use, distribution, and reproduction in any medium, provided you give appropriate credit to the original author(s) and the source, provide a link to the Creative Commons license, and indicate if changes were made. The Creative Commons Public Domain Dedication waiver (http://creativecommons.org/publicdomain/zero/1.0/) applies to the data made available in this article, unless otherwise stated. 

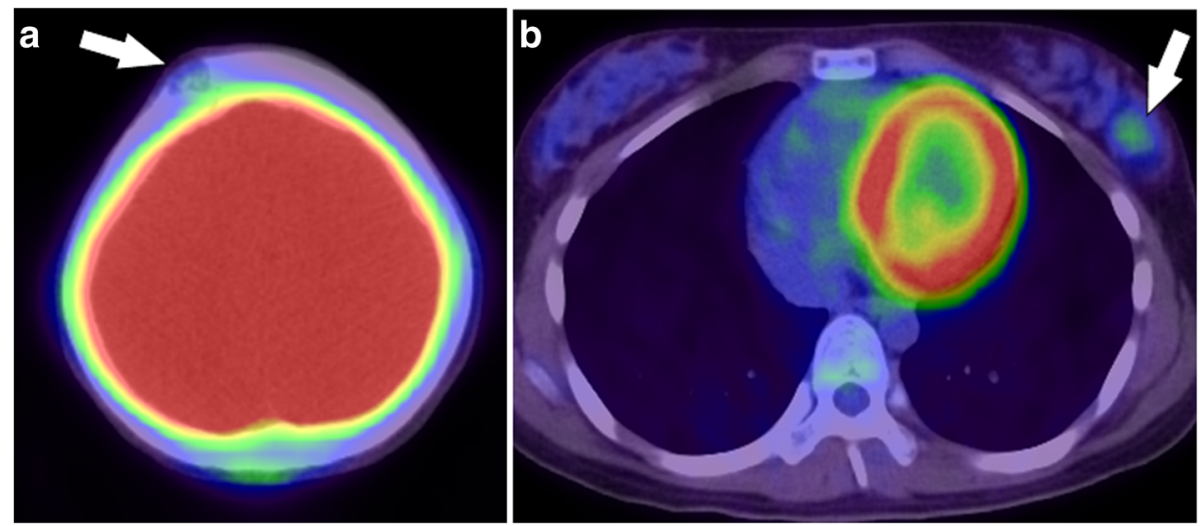

Fig. 1 FDG-PET / CT image findings: Accumulation of fluorodeoxyglucose (FDG) was observed in the right front of the skull (standardized uptake value (SUV)-max 2.8) (a) and left breast (SUV-max 2.4) (b) using FDG-positron emission tomography (PET) / computed tomography (CT)

and vincristine $(2 \mathrm{mg})$; however, the development of severe neutropenia made it difficult to continue administration of these drugs. The patient was then treated with oral administration of $800 \mathrm{mg} /$ day of pazopanib for 1 year, and clinical benefit was achieved. Upon stabilization of the disease, oral administration of pazopanib was discontinued; however, 1 year later, fluorodeoxyglucose accumulation was observed in the right front of the skull (maximum standardized uptake value [SUV-max], 2.8) (Fig. 1a) and in the left breast (SUV-$\max , 2.4$ ) (Fig. 1b) using fluorodeoxyglucose-positron emission tomography/computed tomography.

An elastic, soft tumor, approximately $3 \mathrm{~cm}$ in size, was palpated in the lower lateral region of the left breast. Ultrasonography revealed a hypoechoic, internally heterogeneous mass measuring $22.4 \times 16.2 \times 21.1$ $\mathrm{mm}$ with a rich blood supply (Fig. 2a, b), while magnetic resonance imaging showed a $3-\mathrm{cm}$ sized tumor that was larger than the one found on prior imaging (Fig. 2c). Examination of a core-needle biopsy specimen from the same site showed proliferating tumor cells with abundant foamy cytoplasm, clear nucleoli, and oval nuclei (Fig. 3a, b). The tumor cells tested positive for AE1/AE3, CAM 5.2, vimentin, S-100, $\alpha$-actin, desmin, and HMB 45. The specimen showed negative periodic acid-Schiff (PAS) staining after diastase digestion (Fig. 4a, b); furthermore, the specimen then tested positive for transcription factor E3, resulting in a pathological diagnosis of ASPS (Fig. 4c). Based on the above information, we established a diagnosis of ASPS with left mammary, lung, and cranial metastases. Due to chemoresistance, surgical excision was selected as the mode of treatment; resection of the cranial bone showing metastasis was performed first and partial mastectomy of the left breast was performed in two stages. The mammary tumor was $25 \mathrm{~mm}$ in size, and the cut surface was solid with a reddish gray color (Fig. 5a, b). Histological findings similar to those of the needle biopsy specimen were also obtained in the final pathological diagnosis and resection margins were negative. Postoperative conditions were good, and we are currently monitoring the patient through regular follow-ups (visual palpation every 3 months and semi-annual mammary gland ultrasonography).
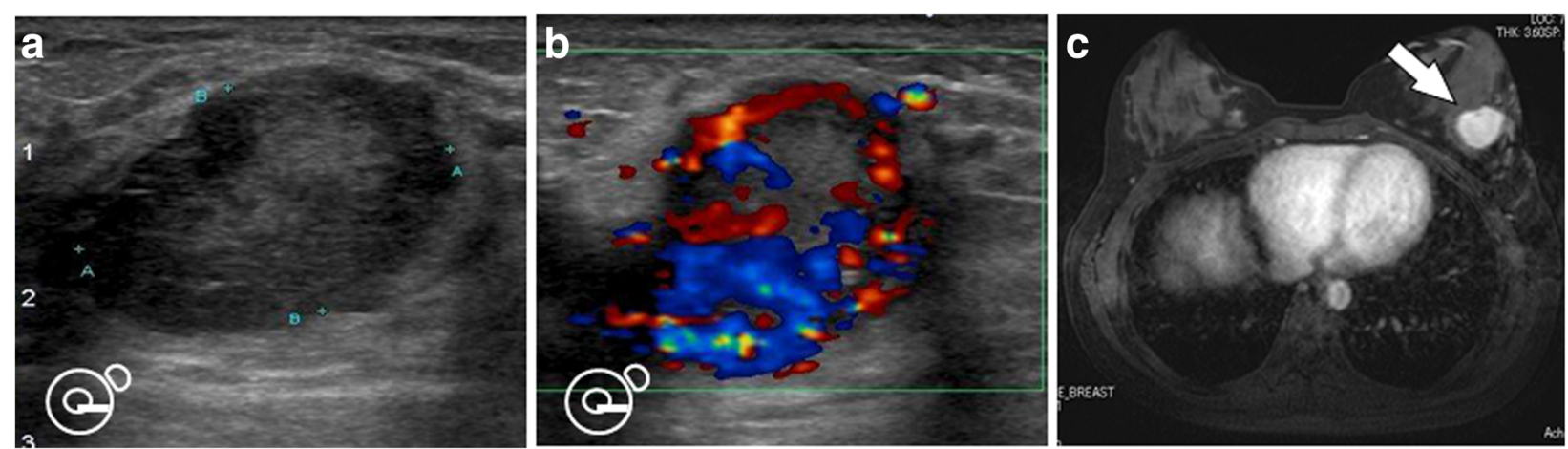

Fig. 2 Ultrasonography and MRI image findings: The mammary tumor was revealed as a hypoechoic, internally heterogeneous mass measuring $22.4 \times 16.2 \times 21.1 \mathrm{~mm}$ (a) with a rich blood supply (b) using ultrasonography, while magnetic resonance imaging findings identified a $3-\mathrm{cm}$ tumor larger than that found on prior imaging (c) (arrow) 

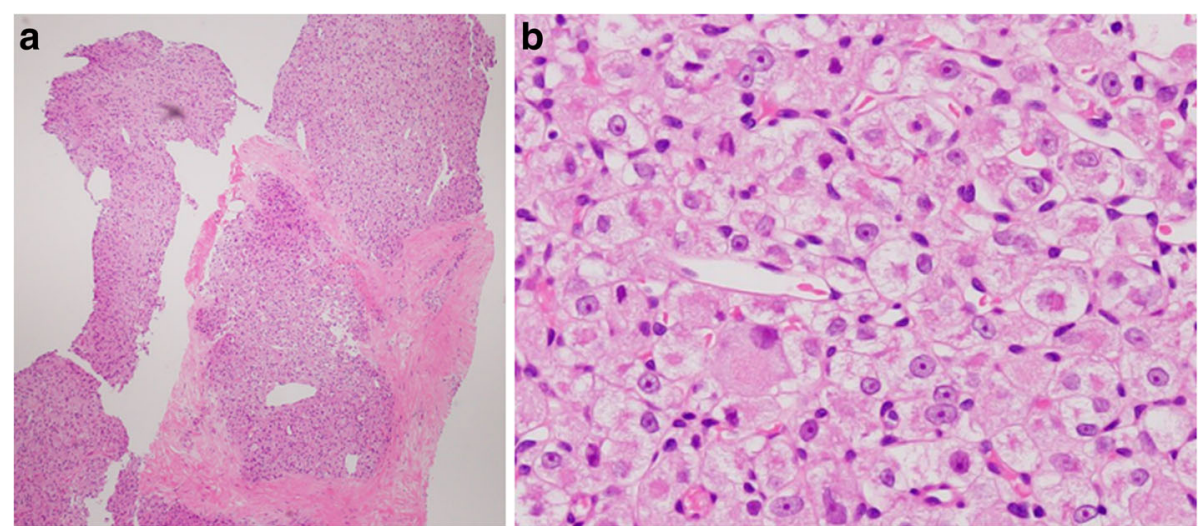

Fig. 3 Pathological diagnosis of core-needle biopsy specimen (Hematoxylin and eosin stain): Tumor cells proliferating to form a solid tumor with comparatively abundant foamy cytoplasm, clear nucleoli, and oval nuclei were found in a core-needle biopsy specimen $(\mathbf{a}: \times 40)(\mathbf{b}: \times 400)$

\section{Discussion and conclusions}

Metastatic tumors of the breast are rare and account for approximately $0.5-2.0 \%$ of all malignant mammary tumors [1]; however, they are successively more prevalent in malignant lymphomas, malignant melanomas, and lung cancer [4]. It has been reported that the rarity of metastases to the mammary glands may be due to the recession and replacement of mammary gland tissues with connective or adipose tissues at the age when cancer development is most likely; the corresponding reduction in blood flow may also be responsible. Clinical findings in such cases often involve a singular mass commonly occurring in the upper lateral part of the breast with no skin involvement or pain, and no overt differences from primary breast cancer are observed. Imaging findings are similar to those of benign tumors [8]; however, the lack of ductal or lobular tumors in pathological diagnosis and retention of the intrinsic structure of the mammary gland are the key differences between benign and metastatic tumors of the breast [9].

Conversely, ASPS is rare and accounts for $0.5-1.0 \%$ of soft-tissue sarcomas; it commonly occurs in young women. In adults, it is often found in the lower limbs, while it commonly occurs in the head and neck in children [2, 10]. At the time of definitive diagnosis, $60-70 \%$ of cases involve distant metastases to the lungs, bones, and brain, and the condition has a poor prognosis with an average survival time of approximately 40 months. Cases with ASPS metastasis to mammary tissue are considered extremely rare and are reported only in 10 previous studies $[5,6,11]$. Orphans et al. [7] reported no difference between the left and right onset (11 29-year-old) in the case of breast metastases from ASPS, and about half of the cases were multiple organ metastases (number of lesions: range 1 3, median 1.5). In our case, we observed juvenile onset and multiple organ metastases. Since the size of the tumor were relatively small, about $2 \mathrm{~cm}$, we performed partial resection of the mammary gland. Pathological histology in such cases is characterized by an alveolar proliferation of atypical cells with circular nuclei and clear cell bodies, intracellular periodic acid-Schiff positivity of the atypical cells, and presence of diastase-resistant and non-resistant glycogen granules [12, 13]. Similar pathological findings were also observed in our case, except that

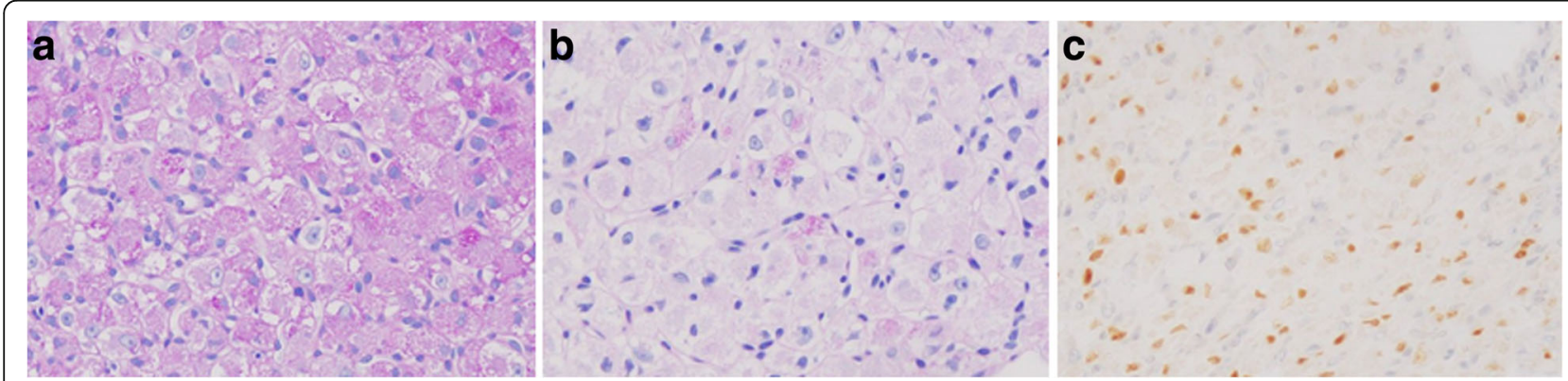

Fig. 4 Pathological diagnosis of core-needle biopsy specimen (Immunohistochemistry): The specimen negatively converted after diastase digestion of periodic acid-Schiff (PAS) staining $(\mathbf{a}, \mathbf{b})$, which was TFE3-positive $(\mathbf{c})(\times 400)$ 

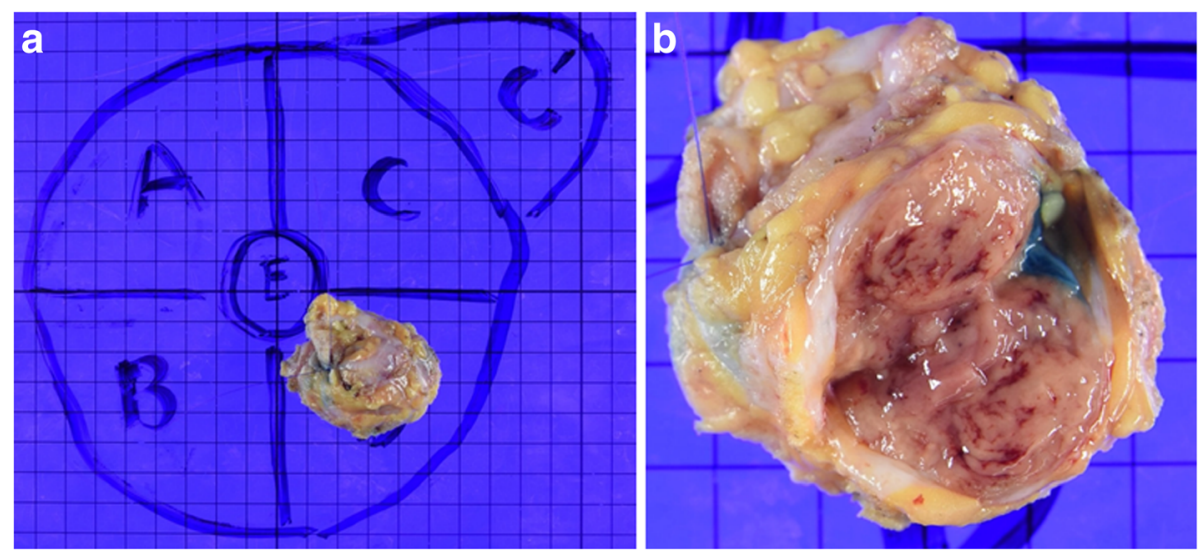

Fig. 5 Macroscopic diagnosis of the resected specimen: The mammary tumor was $25 \mathrm{~mm}$ in size (a), and the cut surface was solid with a reddish gray color (b)

diastase-resistant granules were absent. However, positive expression of transcription factor E3 was confirmed, which is considered to be a pathological characteristic of ASPS. In ASPS, assessment of $\mathrm{t}(\mathrm{X} ; 18)$ translocation using fluorescence in situ hybridization or karyotyping is regarded as the standard diagnosis; however, this test was not used in our case.

Surgical excision is most commonly used for treatment because of chemotherapeutic resistance $[14,15]$. In recent years, a number of reports have indicated the efficacy of the molecular targeted drugs, pazopanib and sunitinib [16, 17], and future development is expected. Pazopanib might not cross the blood-brain barrier and this may be the reason for tumor regrowth in the brain despite treatment with this drug.

We reported an extremely rare case of ASPS with mammary metastasis with some reference-based discussion. In our case, disease control was obtained by a combination of drug therapy and surgical treatment.

\section{Abbreviations}

ASPS: Alveolar soft part sarcoma; CT: Computed tomography;

FDG: Fluorodeoxyglucose; PAS: Periodic acid-Schiff; PET: Positron emission tomography; SUV: Standardized uptake value; TFE3: Transcription factor E3

\section{Acknowledgements}

We thank Yayoi Matsukiyo and Tomomi Okawa (Department of Breast and Endocrine Surgery, Osaka City University Graduate School of Medicine) for helpful advice regarding data management.

\section{Funding}

This study was supported in part by Grants-in Aid for Scientific Research (KAKENHI, Nos. 25461992, 26461957, and 17 K10559) from the Ministry of Education, Science, Sports, Culture and Technology of Japan to Shinichiro Kashiwagi.

\section{Availability of data and materials}

The datasets supporting the conclusions of this article is included within the article.

\section{Authors' contributions}

All authors were involved in the preparation of this manuscript. YA collected the data, and wrote the manuscript. YA, SK, KT, ST, and TT performed the operation and designed the study. MOhs perfomed pathological diagnosis. SK and $\mathrm{KH}$ summarized the data and revised the manuscript. $\mathrm{KH}$ and MOhi made substantial contribution to the study design, performed the operation, and revised the manuscript. All authors read and approved the final manuscript.

\section{Ethics approval and consent to participate}

Written informed consent was obtained from the patient for publication of this Case report and any accompanying images. A copy of the written consent is available for review by the Editor of this journal. This case report study was carried out respecting the Declaration of Helsinki in its current version. Ethical approval: not applicable.

\section{Consent for publication}

Written and informed consent was taken from the patient and the relatives of the participants for publication of this case report and any accompanying images. A copy of the written consent is available for review by the Editorin-Chief of this journal.

\section{Competing interests}

The authors declare that they have no competing interests.

\section{Publisher's Note}

Springer Nature remains neutral with regard to jurisdictional claims in published maps and institutional affiliations.

\section{Author details}

${ }^{1}$ Department of Breast and Endocrine Surgery, Osaka City University Graduate School of Medicine, 1-4-3 Asahi-machi, Abeno-ku, Osaka 545-8585, Japan. ${ }^{2}$ Department of Pediatrics, Osaka City University Graduate School of Medicine, 1-4-3 Asahi-machi, Abeno-ku, Osaka 545-8585, Japan. ${ }^{3}$ Department of Diagnostic Pathology, Osaka City University Graduate School of Medicine, 1-4-3 Asahi-machi, Abeno-ku, Osaka 545-8585, Japan.

Received: 30 August 2018 Accepted: 27 February 2019

Published online: 04 March 2019

\section{References}

1. Christopherson WM, Foote FW Jr, Stewart FW. Alveolar soft-part sarcomas; structurally characteristic tumors of uncertain histogenesis. Cancer. 1952;5(1):100-11.

2. Lieberman PH, Brennan MF, Kimmel M, Erlandson RA, Garin-Chesa P, Flehinger BY. Alveolar soft-part sarcoma. A clinico-pathologic study of half a century. Cancer. 1989;63(1):1-13.

3. Cappabianca S, Grassi R, D'Alessandro P, Del Vecchio A, Maioli A, Donofrio V. Metastasis to the male breast from carcinoma of the urinary bladder. $\mathrm{Br} \mathrm{J}$ Radiol. 2000;73(876):1326-8. 
4. Vergier B, Trojani M, de Mascarel I, Coindre JM, Le Treut A. Metastases to the breast: differential diagnosis from primary breast carcinoma. J Surg Oncol. 1991;48(2):112-6.

5. Hanna NN, O'Donnell K, Wolfe GR. Alveolar soft part sarcoma metastatic to the breast. J Surg Oncol. 1996;61(2):159-62.

6. Madrigrano A, Beach B, Wheeler A, Wapnir I. Metastases to the breast: alveolar soft part sarcoma in adolescents. Clin Breast Cancer. 2008;8(1):92-3.

7. Orphanos G1, loannidis G, loannou R, Zouvani I. Alveolar soft part sarcoma with breast metastases: a case report. Med Oncol. 2013;30(1):342.

8. Belton AL, Stull MA, Grant T, Shepard MH. Mammographic and sonographic findings in metastatic transitional cell carcinoma of the breast. AJR Am J Roentgenol. 1997;168(2):511-2.

9. Hajdu SI, Urban JA. Cancers metastatic to the breast. Cancer. 1972;29(6):1691-6.

10. Flores RJ, Harrison DJ, Federman NC, Furman WL, Huh WW, Broaddus EG, Okcu MF, Venkatramani R. Alveolar soft part sarcoma in children and young adults: A report of 69 cases. Pediatr Blood Cancer. 2018;65(5):e26953.

11. Bychkov A, Sampatanukul P. Alveolar soft part sarcoma presenting as a breast metastasis in a patient with a history of thyroid cancer: a case report. Int J Clin Exp Pathol. 2015;8(8):9731-6.

12. Heimann P, Devalck C, Debusscher C, Sariban E, Vamos E. Alveolar soft-part sarcoma: further evidence by FISH for the involvement of chromosome band 17q25. Genes Chromosomes Cancer. 1998;23(2):194-7.

13. Schoolmeester JK, Carlson J, Keeney GL, Fritchie KJ, Oliva E, Young RH Nucci MR. Alveolar Soft Part Sarcoma of the Female Genital Tract: A Morphologic, Immunohistochemical, and Molecular Cytogenetic Study of 10 Cases With Emphasis on its Distinction From Morphologic Mimics. Am J Surg Pathol. 2017;41(5):622-32.

14. Portera CA Jr, Ho V, Patel SR, Hunt KK, Feig BW, Respondek PM, Yasko AW Benjamin RS, Pollock RE, Pisters PW. Alveolar soft part sarcoma: clinica course and patterns of metastasis in 70 patients treated at a single institution. Cancer. 2001;91(3):585-91.

15. Ogose A, Yazawa Y, Ueda T, Hotta T, Kawashima H, Hatano H, Morita T, Japanese Musculoskeletal Oncology G. Alveolar soft part sarcoma in Japan: multi-institutional study of 57 patients from the Japanese Musculoskeletal Oncology Group. Oncology. 2003;65(1):7-13.

16. Shido Y, Matsuyama Y. Advanced Alveolar Soft Part Sarcoma Treated with Pazopanib over Three Years. Case Rep Oncol Med. 2017:2017:3738562.

17. Stacchiotti S, Negri T, Zaffaroni N, Palassini E, Morosi C, Brich S, Conca E, Bozzi F, Cassinelli G, Gronchi A, et al. Sunitinib in advanced alveolar soft part sarcoma: evidence of a direct antitumor effect. Ann Oncol. 2011;22(7):1682-90.

Ready to submit your research? Choose BMC and benefit from:

- fast, convenient online submission

- thorough peer review by experienced researchers in your field

- rapid publication on acceptance

- support for research data, including large and complex data types

- gold Open Access which fosters wider collaboration and increased citations

- maximum visibility for your research: over $100 \mathrm{M}$ website views per year

At $\mathrm{BMC}$, research is always in progress.

Learn more biomedcentral.com/submissions 